\title{
Adição de complexo enzimático e da granulometria da soja integral desativada melhora desempenho de frangos de corte
}

\author{
Addition of enzymatic complex and deactivated full-fat soybean particle size \\ optimize performance of broilers \\ Michelly Opalinski ${ }^{I}$ Alex MaiorkaII Fábio da Cunha'II Chayane da Rocha ${ }^{\text {II }}$ \\ Sebastião Aparecido Borges ${ }^{\mathrm{IV}}$
}

\section{RESUMO}

O experimento foi conduzido com objetivo de avaliar o efeito da adição de complexo enzimático e da granulometria da soja integral desativada sobre o desempenho de frangos no período de um a 42 dias de idade. Foram utilizados 480 pintos machos da linhagem Ross, distribuídos em um delineamento inteiramente casualizado, em esquema fatorial $2 \times 2$ (enzima x granulometria). As rações experimentais foram formuladas à base de milho, farelo de soja e soja integral desativada $( \pm 1,5 \mathrm{~mm})$, soja integral desativada $( \pm 1,5 \mathrm{~mm})+$ enzima, soja integral desativada $( \pm 4,0 \mathrm{~mm})$ e soja integral desativada $( \pm 4,0 \mathrm{~mm})+$ enzima. O complexo enzimático (xilanase, $\beta$-glucanase, mannase, pectinase e protease) foi adicionado na dosagem de $50 \mathrm{~g} \mathrm{t}^{-1}$ de ração. A adição do complexo enzimático aumentou $(P=0,053)$ em $4 \%$ o consumo de ração e $2,8 \%$ o ganho de peso no período final de criação. $O$ consumo de ração foi aumentado em $3 \%$ no período final $e$ $(P=0,048) 2 \%$ no período total em aves que ingeriram ração com granulometria $1,5 \mathrm{~mm}$. No período inicial, as aves que ingeriram ração com granulometria 4,0mm tiveram aumento de $5 \%$ no ganho de peso e obtiveram os melhores índices de conversão alimentar. A adição do complexo enzimático em dietas à base de soja integral melhora o desempenho de frangos. Não é recomendada a utilização da soja com granulometria $1,5 \mathrm{~mm}$ nas fases iniciais para frangos.

Palavras chave: enzima exógena, desempenho, aves, granulometria, soja integral.

\section{ABSTRACT}

This experiment was carried out to evaluate the effect of the enzymatic complex addition and deactivated fullfat soybean particle size on performance of broilers in the period from 1 to 42 days of age. Four hundred and eighty male broiler chicks from the Ross strain were used, allotted to a completely randomized factorial scheme $2 x 2$ (enzyme $x$ particle size). The experimental diets were based on corn, soybean meal and $( \pm 1.5 \mathrm{~mm}$ or $\pm 4.0 \mathrm{~mm})$ deactivated full-fat soybean, with or without enzyme. The enzymatic complex (xylanase, b-glucanase, mannase, pectinase and protease) was supplied in the dose of $50 \mathrm{~g} \mathrm{t}^{-1}$ ration. The enzymatic complex addition increased $(P=0.0531)$ the diet intake in $4 \%$ and the weight gain in $2.8 \%$ in the final period. The feed intake increased $3 \%$ in the final period and $2 \%$ in the total period in poultry that were fed with fine particle size diet. In the initial period, the chicks that ingested the coarse particle size diet had a 5\% weight gain increase and had the greater feed rates. The addition of the enzymatic complex in diets with deactivated full-fat soybean improves the performance of chickens. The use of the soy with fine particle size $(1,5 \mathrm{~mm})$ in the initial phases for chickens is not recommended.

Key words: chickens, exogenous enzyme, full-fat soybean, particle sizes, performance.

\section{INTRODUÇÃO}

O crescimento na produção de frangos de corte tem levado nutricionistas a buscar soluções a fim de atender as necessidades nutricionais das aves que, devido ao rápido crescimento, passaram a exigir alimentos de melhor qualidade. Alguns fatores, como linhagem, sexo, idade, temperatura ambiente, densidade, forma física e granulometria da ração, interferem no desempenho de frangos de corte.

'Departamento de Zootecnia (DZ), Universidade Federal do Paraná (UFPR), Curitiba, PR, Brasil. Endereço para correspondência: Rodovia PR 218, Km 6, 87701970, Zona Rural, Paranavaí, PR, Brasil. E-mail: michellyopalinski@gmail.com.

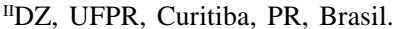

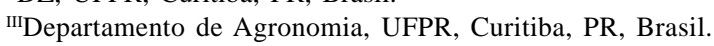

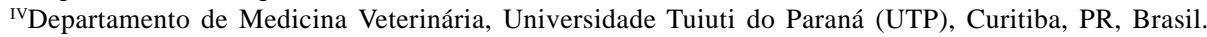


O tamanho das partículas do alimento e a forma física da ração influenciam sua velocidade de passagem no trato gastrintestinal (MACARI et al., 1994). Assim, as aves alimentadas com rações fareladas com granulometria fina podem ter seu consumo reduzido e consequentemente obterem menor ganho de peso. Contudo, aves que recebem rações com granulometria mais grossa têm a velocidade de passagem das partículas maiores reduzida, resultando em melhor ganho de peso (NIR et al., 1994).

Estudos anteriores que avaliaram o efeito da temperatura, os níveis de energia e o tamanho das partículas sobre o desempenho de frangos demonstram que animais ingerindo ração com granulometria menor apresentaram melhor desempenho (LOTT et al., 1992). Também foi verificado por DAHLKE (2000) que rações fareladas com granulometria mais fina resultaram em conversão alimentar e ganho de peso inferiores quando comparadas às rações com granulometria mais grossa, segundo o autor isso se explica devido ao fato de haver menor ingestão de ração por parte das aves.

O grão de soja integral apresenta fatores antinutricionais como os inibidores de tripsina, lectinas e polissacarídeos não amiláceos. Porém, a indústria aplica processamentos térmicos, como a extrusão e a tostagem, com intuito de desativar os compostos antinutritivos do grão integral cru. Esses processamentos melhoram a digestibilidade dos nutrientes e o ganho de peso das aves, entretanto, existem alguns fatores antinutricionais e constituintes de baixa digestibilidade que não são afetados, seja totalmente ou parcialmente, por eses processos.

A presença dos polissacarídeos não amiláceos solúveis no lúmen intestinal aumenta a viscosidade da digesta em razão da formação de polímeros ou géis com a água, comprometendo a digestão e a absorção dos nutrientes, por dificultar a ação das enzimas digestivas e a difusão das substâncias relacionadas com a digestão e absorção. O aumento da viscosidade no intestino afeta a digestibilidade do amido, da proteína e dos lipídeos (NUNES et al., 2001).

Pesquisas demonstram respostas positivas à digestibilidade de nutrientes e ao desempenho de aves alimentadas com rações à base de milho e soja, quando estas foram suplementadas com enzimas como carboidrases, proteases, pectinases e alfa galactosidades (BRITO et al., 2006.; TORRES et al., 2003; COSTA et al., 2004).

A utilização de aditivos enzimáticos nas dietas pode oportunizar reduções nos níveis de energia metabolizável, proteína e aminoácidos nas formulações de rações para frangos de corte, sendo constatada uma redução mínima de 2,5\%, o que viabiliza o custo das rações, mesmo incluindo o custo da enzima (SOTOSALANOVA et al., 1996). Com base no exposto, este trabalho teve como objetivo avaliar o efeito da granulometria da soja integral e da adição de enzima exógena sobre o desempenho de frangos de corte.

\section{MATERIAL E MÉTODOS}

O experimento foi realizado nas instalações da Universidade Federal do Paraná. As aves foram alojadas em galpão convencional dividido em boxes, com dimensões 1,5x1,0m e piso de maravalha reutilizada de galinhas com 20 semanas. Para o aquecimento dos pintinhos, foi utilizada uma campânula elétrica equipada com lâmpada infravermelho para cada box. Foram utilizados 480 pintos de corte machos de um dia de idade da linhagem Ross, com peso médio de 44g. Em cada , foram alojados 20 animais, totalizando seis repetições por tratamento. Os pintos de um dia foram pesados assim que chegaram ao aviário e em seguida foram alojados em boxes. Os animais receberam água e ração à vontade durante todo o experimento e 24 horas de luz. À noite a iluminação foi artificial e durante o dia utilizou-se iluminação natural.

As rações experimentais foram formuladas à base de milho, farelo de soja e soja integral desativada com granulometria de $1,5 \mathrm{~mm}$ ou $4,0 \mathrm{~mm}$ adicionadas ou não de enzimas. O complexo enzimático (xilanase, ßglucanase, mannase, pectinase e protease) foi adicionado na dosagem de $50 \mathrm{~g} \mathrm{t}^{-1}$ de ração, considerando-se que esta contribuía com 50kcal EM $\mathrm{kg}^{-1}$ de ração. O inerte utilizado em substituição à enzima foi o caulim. Foram realizadas pesagens das aves e da ração no $7^{\circ}$, no $21^{\circ}$ e no $42^{\circ}$ dia de idade para determinação do peso vivo, ganho de peso e consumo de ração no período. A conversão alimentar foi obtida pela relação entre consumo de ração e ganho de peso no período. As aves foram distribuídas em um delineamento inteiramente casualizado, em esquema fatorial 2x2 (enzima x granulometria). Os dados de consumo de ração, ganho de peso e conversão alimentar foram submetidos à análise de variância.

\section{RESULTADOS E DISCUSSÃO}

Os resultados apresentados (Tabela 1) demonstram que o consumo de alimento foi afetado significativamente $(\mathrm{P}=0,05)$, pela adição do complexo enzimático no período de 1-42 dias de idade, e a adição da enzima aumentou o consumo de ração. Resultados semelhantes foram encontrados por COSTA et al. (2004), os quais não observaram diferença no consumo 
Tabela 1 - Efeito da adição de complexo enzimático e da granulometria da soja integral desativada sobre o consumo de ração de frangos.

\begin{tabular}{|c|c|c|c|c|}
\hline \multirow{2}{*}{\multicolumn{2}{|c|}{ Efeitos principais }} & \multicolumn{3}{|c|}{------Consumo de ração (kg)------ } \\
\hline & & $1-7$ dias & 1-21 dias & 1-42 dias \\
\hline \multirow{2}{*}{ Enzima } & Com & 0,163 & 1,031 & 3,788 \\
\hline & Sem & 0,163 & 1,068 & 3,715 \\
\hline \multirow{3}{*}{$\begin{array}{l}\text { Granulometria } \\
\text { (mm) }\end{array}$} & $1,5 \mathrm{~mm}$ & 0,163 & 1,046 & 3,789a \\
\hline & $4,0 \mathrm{~mm}$ & 0,162 & 1,053 & $3,714 b$ \\
\hline & & \multicolumn{3}{|c|}{---------Probabilidade--------- } \\
\hline \multicolumn{2}{|c|}{ Enzimas (A) } & 0,983 & 0,060 & 0,053 \\
\hline \multicolumn{2}{|c|}{ Granulometria (B) } & 0,545 & 0,735 & 0,048 \\
\hline \multicolumn{2}{|l|}{$A \times B$} & 0,647 & 0,690 & 0,288 \\
\hline
\end{tabular}

entre aves suplementadas ou não com complexo enzimático na ração, no período inicial de criação; no entanto, no período final de criação, as aves suplementadas obtiveram maior consumo em relação às aves não suplementadas. Provavelmente esa variação no consumo de ração esteja relacionada ao equivalente energético da enzima proposto nas fórmulas (50kcal EM kg-1 de ração).

A granulometria da soja afetou o consumo de ração no período de um a 42 dias de idade das aves. No período total de criação, a ração com soja de granulometria $1,5 \mathrm{~mm}$ proporcionou um aumento de $2 \%$ no consumo das aves. Os resultados obtidos discordam de NIR et al. (1994), DAHLKE (2000) e LÓPEZ \& BAIÃO (2002), os quais observaram que rações fareladas com granulometria mais fina resultam em consumo alimentar inferior quando comparadas às rações com granulometria mais grossa. Considerando que na composição da ração o milho e os demais ingredientes permaneceram com a mesma inclusão e granulometria, a redução na granulometria da soja pode ter interferido no peristaltismo intestinal das aves, podendo então ter ocorrido um aumento na taxa de passagem.

Os resultados apresentados (Tabela 2) demonstram que o ganho de peso foi influenciado significativamente pela adição do complexo enzimático no período total de criação. Considerando o período total de criação, a adição de enzimas aumentou 2,8\% o ganho de peso, em relação às dietas não suplementadas. ZANELLA (1998) verificou efeito da suplementação enzimática em todas as fases de criação com exceção de 38 a 45 dias, e o aumento no ganho de peso das aves foi 2,2\%. BRITO et al. (2006) verificaram que a adição do complexo multienzimático proporcionou aumento de 3,8\% no ganho de peso das aves. Essa melhora no ganho de peso com a suplementação enzimática pode estar associada à melhor digestibilidade nessas dietas (OPALINSKI, 2006).

A granulometria da soja influenciou o ganho de peso no período de um a sete dias de idade. No período inicial, as aves que ingeriram ração com soja granulometria 4,0mm tiveram aumento de $5 \%$ no ganho de peso em relação às aves que foram alimentadas com ração composta por soja de granulometria 1,5mm. Resultados semelhantes foram evidenciados por LOTT et al. (1992), os quais demonstraram que animais que ingeriram ração com granulometria menor apresentaram melhor desempenho.

Os resultados apresentados (Tabela 3) demonstram que a conversão alimentar não foi afetada $(\mathrm{P}<0,05)$ pela adição do complexo enzimático em nenhum dos períodos. CLEMENTINO et al. (2002) verificaram que no período de um a 21 dias, frangos alimentados com dietas contendo níveis nutricionais normais com enzimas e níveis proteicos e energéticos reduzidos em 2 e 3\% suplementadas com 2 e 3\% de enzimas, respectivamente, obtiveram os melhores resultados para conversão alimentar se comparados com frangos alimentados com dietas com níveis normais sem suplementação enzimática e com dietas com níveis nutricionais reduzidos em $1 \%$ suplementas com 1\% de enzimas. Esse resultado é semelhante aos resultados observados por COSTA et al. (2004). Em outros estudos, ZANELLA (1998) e TORRES et al. (2003) não observaram diferença estatística para conversão alimentar entre os tratamentos com suplementação enzimática, com níveis reduzidos de energia em relação aos tratamentos sem suplementação enzimática com níveis normais de energia, evidenciando a eficiência das enzimas no aproveitamento energético das dietas.

Tabela 2 - Efeito da adição de complexo enzimático e da granulometria da soja integral desativada sobre o ganho de peso de frangos.

\begin{tabular}{|c|c|c|c|c|}
\hline \multirow{2}{*}{\multicolumn{2}{|c|}{ Efeitos principais }} & \multicolumn{3}{|c|}{--------Ganho de Peso (kg)-------- } \\
\hline & & $1-7$ dias & $1-21$ dias & 1-42 dias \\
\hline \multirow[t]{2}{*}{ Enzimas } & Com & 0,136 & 0,787 & $2,402 a$ \\
\hline & Sem & 0,136 & 0,799 & 2,334b \\
\hline \multirow{3}{*}{$\begin{array}{c}\text { Granulometria, } \\
\text { mm }\end{array}$} & 1,5 & $0,133 b$ & 0,780 & 2,387 \\
\hline & 4,0 & $0,140^{\mathrm{a}}$ & 0,806 & 2,349 \\
\hline & & \multicolumn{3}{|c|}{-----------Probabilidade----------- } \\
\hline \multicolumn{2}{|c|}{ Enzimas (A) } & 0,825 & 0,403 & 0,007 \\
\hline \multicolumn{2}{|c|}{ Granulometria (B) } & 0,004 & 0,066 & 0,114 \\
\hline \multicolumn{2}{|l|}{$A \times B$} & 0,086 & 0,457 & 0,710 \\
\hline
\end{tabular}


Tabela 3 - Efeito da adição de complexo enzimático e da granulometria da soja integral desativada sobre a conversão alimentar de frangos.

\begin{tabular}{|c|c|c|c|c|}
\hline \multirow{2}{*}{\multicolumn{2}{|c|}{ Efeitos principais }} & \multicolumn{3}{|c|}{------Conversão Alimentar------ } \\
\hline & & 1-7dias & $1-21$ dias & 1-42 dias \\
\hline \multirow[t]{2}{*}{ Enzima } & Com & 1,199 & 1,311 & 1,577 \\
\hline & Sem & 1,196 & 1,338 & 1,592 \\
\hline \multirow{3}{*}{$\begin{array}{c}\text { Granulometria, } \\
\mathrm{mm}\end{array}$} & $1,5 \mathrm{~mm}$ & $1,234 b$ & $1,343 b$ & 1,588 \\
\hline & $4,0 \mathrm{~mm}$ & $1,162 \mathrm{a}$ & $1,306 a$ & 1,581 \\
\hline & & \multicolumn{3}{|c|}{---------Probabilidade--------- } \\
\hline \multicolumn{2}{|c|}{ Enzima (A) } & 0,843 & 0,136 & 0,188 \\
\hline \multicolumn{2}{|c|}{ Granulometria (B) } & 0,000 & 0,045 & 0,533 \\
\hline \multicolumn{2}{|l|}{$A \times B$} & 0,082 & 0,651 & 0,056 \\
\hline
\end{tabular}

A conversão alimentar foi afetada significativamente pela granulometria da soja nos períodos de um a sete e um a 21 dias. No período de um a sete dias, as aves que consumiram ração com soja com granulometria de $4,0 \mathrm{~mm}$ obtiveram resultado $6 \%$ melhor em relação às aves que consumiram ração com soja com granulometria de $1,5 \mathrm{~mm}$. No período de um a 21 dias de idade, a soja com granulometria de 4,0mm proporcionou melhores resultados para conversão alimentar. Esses resultados concordam com LÓPEZ \& BAIÃO (2004), os quais verificaram, em dietas fareladas para frango de corte, que a granulometria mais grossa proporcionou melhores resultados. Já MURTA et al. (2004), trabalhando com diferentes granulometrias de sorgo (1,20mm; 4,76mm; 6,35mm e 9,52mm) para frangos de oito a 42 dias de idade, não encontraram diferença entre nenhum dos tratamentos.

\section{CONCLUSÕES}

De acordo com os resultados apresentados, conclui-se que o consumo de ração e o ganho de peso são afetados pela adição do complexo enzimático (xilanase, ß-glucanase, mannanase, pectinase e protease) na ração de frangos de corte, no período de um a 42 dias de idade das aves. Em dietas à base de soja integral, a adição do complexo enzimático melhora o desempenho de frangos de corte.

\section{REFERÊNCIAS}

BRITO, C.O. et al. Adição de complexo multienzimático em dietas à base de soja extrusada e desempenho de pintos de corte. Revista Brasileira de Zootecnia, v.35, p.457-461, 2006. Disponível em: <http://www.scielo.br/pdf/rbz/v35n2/a17v35n2.pdf>. Acesso em: 11 nov. 2009. doi: 10.1590/S1516-35982006000200017.
BRITO, C.O. et al. Adição de complexo multienzimático em dietas à base de soja extrusada: valores energéticos e digestibilidade de nutrientes em pintos de corte. Revista Brasileira de Zootecnia, v.35, n.3, supl., p.1047-1055, 2006. Disponível em: <http://www.scielo.br/pdf/rbz/v35n2/a17v35n2.pdf>. Acesso em: 11 nov. 2009. doi: 10.1590/S1516-35982006000400015.

CLEMENTINO, R.H. et al. Efeito dos níveis de enzimas sobre o desempenho de frangos de corte no período de 1 a 21 dias de idade. In: REUNIÃO ANUAL DA SOCIEDADE BRASILEIRA DE ZOOTECNIA, 39., 2002, Recife, PE. Anais... Recife: Sociedade Brasileira de Zootecnia, 2002. CD-ROM.

COSTA, F.G. et al. Utilização de um complexo multienzimático em dietas de frangos de corte. Ciência Animal Brasileira, v.5, p.63-71, 2004.

DAHLKE, F. Tamanho da partícula do milho e forma física da ração para frangos de corte e seus efeitos sobre o desempenho, dinâmica intestinal e rendimento de carcaça. 2000. 98f. Dissertação (Mestrado em Zootecnia) Programa de Pósgraduação em Agronomia, Universidade Federal do Rio Grande do Sul, Porto Alegre, RS.

LÓPEZ, C.A.A; BAIÃO, N.C. Efeitos da moagem dos ingredientes e da forma física da ração sobre o desempenho de frangos de corte. Arquivo Brasileiro de Medicina Veterinária e Zootecnia, v.54, n.2, p.189-195, 2002. Disponível em: <http://www.scielo.br/scielo.php?pid=S010209352002000200010\&script $=$ sci_arttext\&tlng=pt $>$. Acesso em: 17 fev. 2009. doi: 10.1590/S0102-09352002000200010.

LÓPEZ, C.A.A; BAIÃO, N.C. Efeitos do tamanho da partícula e da forma física da ração sobre o desempenho, rendimento de carcaça e peso dos órgãos digestivos de frangos de corte. Arquivo Brasileiro de Medicina Veterinária e Zootecnia,v.56, n.2, p.214-221, 2004. Disponível em: <http://www.scielo.br/ scielo.php?pid=S010209352004000200012\&script=sci_arttext\&tlng=pt $>$. Acesso em: 17 fev. 2009. doi: 10.1590/S010209352004000200012 .

LOTT, B.D. et al. The effect of temperature, dietary energy level and corn particle size on broiler performance. Poultry Science, v.71 p.618-624, 1992.

MACARI, M. et al. Fisiologia aviária aplicada a frangos de corte. Jaboticabal: FUNESP/UNESP, 1994. 296p.

MURTA, G.P.O. et al. Efeito da moagem do sorgo grão sobre o desempenho de frangos de corte. Revista Brasileira de Ciência Avícola, v.6, p.32, 2004.

NIR, I. et al. Effect of grain particle size performance. 2. Grain texture interactions. Poultry Science, v.73 p.781-791, 1994.

NUNES, R.V. et al. Fatores antinutricionais dos ingredientes destinados à alimentação animal. In: SIMPÓSIO SOBRE INGREDIENTES NA ALIMENTAÇÃO ANIMAL, 2001, Campinas, SP. Proceedings... Campinas: CBNA, 2001. p. 235-272.

OPALINSKI, M. Utilização de enzima e soja integral em rações para frangos formuladas com ingredientes 
alternativos com base em aminoácidos digestíveis e totais. 2006. 105f. Dissertação (Mestrado em Ciências Veterinárias - Nutrição e Alimentação Animal) - Pós-graduação em Ciências Veterinárias, Universidade Federal do Paraná, Curitiba, PR.

SOTO-SALANOVA, M.F. et al. Uso de enzimas em dietas de milho e soja para frangos de corte. In: CONFERÊNCIA APINCO DE CIÊNCIA E TECNOLOGIA AVÍCOLAS, 1996, Curitiba, PR. Anais... Curitiba: APINCO, 1996. p.71-76.
TORRES, D.M. et al. Dietas à base de milho e farelo de soja suplementadas com enzimas na alimentação de frangos de corte. Ciência e Agrotecnologia, Lavras, v.27, n.1, p.199-205, 2003.

ZANELLA, I. Suplementação enzimática em dietas a base de milho e sojas processadas sobre a digestibilidade de nutrientes e desempenho de frangos de corte. 1998. 179f. Tese (Doutorado em Zootecnia - Produção Animal) Faculdade de Ciências Agrárias e Veterinárias, Universidade Estadual Paulista, Jaboticabal, SP. 